\title{
El maquinismo urbano hecho celuloide (1925-1936)
}

\author{
Luis FERLA \\ Universidade Federal de São Paulo \\ ferla@unifesp.br
}

Recibido: $15 / 11 / 2011$

Aceptado: 24/02/2012

\section{RESUMEN}

La metrópolis industrial constituyó un fenómeno de sincronización sin precedentes, capaz de impresionar el imaginario y la cultura de la época. Por consiguiente también el cine termina por reflejar la percepción social dirigida hacia la novedad de la metrópolis industrial y las metáforas relacionadas con el universo de las máquinas que produjo tratarían de traducir la sincronía urbana al celuloide, ya sea en forma apologética o crítica. Subyace a todas las perspectivas una perplejidad legítima con lo mucho que había de desconocido e inédito en la vivencia cotidiana en la metrópolis. Este estudio tiene como objetivo identificar en películas del periodo de entreguerras la presencia de ese discurso vinculado a la máquina y dedicado a la gran ciudad, además de buscar reconocer los principales mecanismos utilizados para transponerlo al lenguaje cinematográfico.

Palabras clave: fenómenos de la modernidad, historia de las ciudades, historia del cine, historia del cuerpo, sociedad industrial.

\section{The Urban Machinism Translated to Celluloid (1925-1936)}

\begin{abstract}
Industrial metropolises have become an unprecedented synchronization phenomenon, which has been capable of captivating the imagination and influencing the culture of large city dwellers. As a result, the cinema also ended up reflecting the social awareness of the industrial metropolis as a novelty. The machine metaphors that it generated were meant to convey all the urban synchronicity through the celluloid film, whether apologetically or critically. Underlying those new outlooks on urban life, there was a legitimate sense of awe before everything that was unknown and unprecedented about the daily events taking place in a metropolis. This study aims to identify the presence of the discourse of machinism dedicated to big cities in films of the interwar period.
\end{abstract}

Key words: modern time's phenomena, history of the cities, history of the cinema, history of the body, industrial society.

Sumario: 1. La ciudad moderna como objeto del cine. 2. La sincronización urbana como fenómeno de la realidad. 3. La sincronización urbana en el cine. 4. Conclusión. 5. Bibliografía. 6. Filmografía. 


\section{La ciudad moderna como objeto del cine}

En la primera mitad del siglo pasado, la ciudad se convertía en un objeto de la cultura y del pensamiento. Así, el expresionismo pictórico de Ernst Kirchner dedicado a la Berlín de su tiempo, o el clásico texto de Georg Simmel, La metrópolis y la vida mental, más que idiosincrásicos, representan un amplio movimiento intelectual hacia la gran ciudad ${ }^{1}$. La industrialización no sólo produjo un espacio urbano de una magnitud casi desconocida en la historia, sino también de una naturaleza desconcertantemente nueva. Además de crecer mucho y rápidamente, las ciudades lo hacían de una manera que las volvía irreconocibles ${ }^{2}$. La metrópolis industrial había incorporado las sucesivas revoluciones en los transportes a partir del surgimiento del tren en la primera mitad del siglo XIX, lo que a su vez permitió una creciente especialización espacial de su territorio. La vivienda del rico y del pobre se alejaban, la administración, el comercio y la industria producían sus propios y característicos paisajes locales. Con lo cual la ciudad moderna haría del movimiento y de la circulación sus marcas identitarias. Y aún más, los habitantes de la metrópolis pasaron a experimentar una impregnación tecnológica sin precedentes en su vida cotidiana, que a su vez demandaba radicales adaptaciones en sus sensibilidades. Se puede considerar el texto citado de Georg Simmel como un marco inaugural en la búsqueda por la comprensión de esos fenómenos al proponer, ya en 1902, la relación entre la urbanización y la intensificación de los estímulos nerviosos ${ }^{3}$. Su planteamiento influiría en el pensamiento de Walter Benjamin y Siegfried Kracauer, configurando los tres la llamada concepción neurológica de la modernidad ${ }^{4}$. Al analizar el legado de esos autores y sus condicionantes históricos, Ben Singer propone la siguiente síntesis:

La modernidad implicó un mundo fenomenal - específicamente urbano - notoriamente más rápido, caótico, fragmentado y desorientador que en las fases anteriores de la cultura humana. En medio a la turbulencia sin precedentes de tráfico, ruido, paneles, señales de tráfico, multitudes empujándose, vidrieras y anuncios de la gran ciudad, el individuo se enfrentó a una nueva intensidad de estimulación sensorial. La metrópolis sometió el individuo a un bombardeo de impresiones, choques y sobresaltos. El ritmo de vida se volvió también más frenético, acelerado por las nuevas formas de transporte

\footnotetext{
1 SIMMEL, Georg: “A metrópole e a vida mental”, en Otávio Guilherme VELHO (org.): O fenômeno urbano, Rio de Janeiro, Zahar, 1967, pp. 13-28 (original publicado en 1903, con el título Die Großstädte und das Geistesleben).

2 No tiene sentido cansar al lector con datos referentes a tal hecho, ampliamente conocidos. Tal vez para el lector no brasileño sería interesante informar los referidos a la ciudad de São Paulo, uno de los objetos de ese artículo y la ciudad del país que presentó el crecimiento poblacional más impresionante en el periodo: en 1872 contaba con 31 mil habitantes; en el año de 1940, el censo demográfico acusaría 1.326.261 habitantes (PINTO, Maria Inez Machado Borges: Cotidiano e sobrevivência: a vida do trabalhador pobre na cidade de São Paulo (1890-1914), São Paulo, Edusp, 1994, pp. 65).

3 SIMMEL, Georg: “A metrópole...”, pp. 115-6.

4 SINGER, Ben: "Modernidade, hiperestímulo e o início do sensacionalismo popular", en Leo CHARNEY y Vanessa SCHWARTZ: O cinema e a invenção da vida moderna, São Paulo, Cosac \& Naify, 2001, pp. 115-148 (publicado originalmente en 1995 por la University of California Press, con el título Cinema and the invention of modern life).
} 
rápido, por los horarios apremiantes del capitalismo moderno y por la velocidad siempre acelerada de la línea de montaje ${ }^{5}$.

Por fin, no menos impresionantes deberían ser los escándalos del trabajo masificado, de la miseria ostensiva y de la multitud amenazadora que la sociedad capitalista producía en profusión en las grandes ciudades de la época.

No debe sorprender, por lo tanto, que el espacio urbano adquiriera entonces un notable protagonismo fílmico. ${ }^{6}$ De hecho, el cine se ocuparía recurrentemente de la ciudad. Más allá de escenario, no pocas veces la convertiría en tema y personaje. Es ese precisamente el caso de las películas de sinfonía urbana, prácticamente un género propio que se difundía internacionalmente en las décadas de 1920 y 1930. Se puede identificar sus marcos iniciales en las películas Manhatta, de Charles Sheeler y Paul Strand, de 1921, y Sólo las horas (Rien Que les Heures), del brasileño Alberto Cavalcanti, quien filmó París en el año 1926. Sus congéneres se sucedieron, destacándose Berlín, Sinfonía de una gran ciudad (Berlin, Die Sinfonie der Großstadt), de Walther Ruttmann, filmado en 1927; y São Paulo, Sinfonia da Metrópole, de Rodolfo Lustig y Adalberto Kemeny, que surgió en las pantallas dos años después, casi simultáneamente al formidable experimento de Dziga Vertov en El hombre con la cámara (Chelovek s kino-apparatom), con escenas producidas a partir de las ciudades de Odessa y Moscú. La lista podría aún incluir filmes como Lluvia (Regen), de Joris Ivens, con imágenes de la Ámsterdam de 1929; o los trabajos de László Moholy-Nagy, Impresiones del viejo puerto de Marsella (Impressionen vom alten marseiller Hafen (vieux port)), de 1929, y Naturaleza muerta en Berlín (Berliner Stilleben), de 1931, que retratan Marsella y Berlín, respectivamente. Además de esas sinfonías fílmicas, invariablemente dedicadas al paisaje urbano y a su transformación a lo largo del día, la gran ciudad merecería un tratamiento privilegiado en varias otras producciones, como en Paris dormido (Paris qui dort), de René Clair, de 1925; Metrópolis, de Fritz Lang, de 1927; y Tiempos Modernos (Modern Times), de Charles Chaplin, de 1936. En todas, y seguramente en muchas otras, a la ciudad se le otorgó un protagonismo que en sí mismo debe ser objeto pertinente de análisis por parte del historiador.

Para acercarnos a la sensibilidad de los autores y consumidores de aquellas películas, hace falta tener presente la ya referida «novedad» de la metrópolis industrial, fenómeno relativamente reciente y en muchos sentidos verdaderamente inédito en la historia, poco comprendido por sus protagonistas y capaz de provocar fascinación y horror con iguales intensidades. Al referirse, por ejemplo, a la São Paulo de aquel periodo, Nicolau Sevcenko afirma que la «maciza mayoría de la población ignoraba completamente la experiencia de vivir en una metrópolis, hasta el momento en que se vio inadvertidamente envuelta en una» ${ }^{7}$.

\footnotetext{
5 SINGER, Ben: "Modernidade, hiperestímulo...", p. 116 (traducción libre).

6 Incluso porque el propio surgimiento del cine y su extraordinaria difusión son expresiones paradigmáticas de los fenómenos de la modernidad y de la afirmación de la sociedad industrial aquí asociados a la vida en las metrópolis. Dicho de otra manera, el cine es hijo legítimo de la sociedad industrial y urbana, como lo demuestran varios avances científicos y tecnológicos asociados con su surgimiento (la electricidad, la fotografía, la química, los estudios de movimiento, etc.).

7 SEVCENKO, Nicolau: Orfeu extático na metrópole: São Paulo, sociedade e cultura nos frementes anos 20, São Paulo, Cia das Letras, 1998, p. 40 (traducción libre).
} 
Así que entre los filmes de la época podemos encontrar tanto el pesimismo sombrío de Metrópolis, como el ufanarse «nacional-progresista» de São Paulo, Sinfonia da Metrópole, pasando por la modernidad radical y cargada de ambigüedades del análogo berlinés. El problema que se impone ahora es identificar los recortes fenoménicos que produjeron estas películas y qué discursos resultaron de tales operaciones. En ese sentido, no es difícil constatar que las nuevas configuraciones de tiempo y espacio que la sociedad industrial le confirió a las grandes ciudades es uno de los temas que más fuertemente condicionaron las películas en cuestión.

\section{La sincronización urbana como fenómeno de la realidad}

Así sucedió porque la metrópolis industrial representaba un fenómeno de sincronización sin precedentes en la historia. Cuerpos humanos, máquinas, mercancías, medios de transporte, tecnologías de comunicación, todo lo que componía el paisaje y el contexto urbanos lo hacía como parte articulada de un todo sistémico y ajustado. Retomando el texto de Simmel, es significativo que se encuentren allí los primeros intentos teóricos dedicados a la comprensión del tema:

Las relaciones y quehaceres del metropolitano típico son normalmente tan múltiples y complejos que si no hubiera la más estricta puntualidad en los compromisos y servicios, toda la estructura se rompería y caería en un caos inextricable. Esta necesidad se crea más que nada por la agregación de tantas personas con intereses tan diferenciados que deben integrar sus relaciones y actividades en un organismo altamente complejo. Si todos los relojes de Berlín se pusieran a funcionar en sentidos diferentes, aunque sólo por una hora, toda la vida económica y las comunicaciones de la ciudad se verían afectadas por mucho tiempo ${ }^{8}$.

Norbert Elias es asumidamente tributario de tales reflexiones. Su análisis apunta hacia la importancia de las nuevas percepciones de tiempo que la sociedad industrial produjo para la construcción cotidiana de esa sincronización. Para el pensador alemán, cada individuo tiene que adaptar sus actividades «a la presencia de un número creciente de semejantes», lo que incluía los actos de «levantarse y acostarse», cada vez más asociados a horarios determinados, disciplinados a su vez por un «rigor cada vez mayor». Lo cual significaba la necesidad de aprender a considerar con precisión «en qué momento del futuro se deseaba o se debería hacer esto o lo otro». El condicionamiento sociohistórico para tales cambios reposaría en la articulación entre fenómenos que se desarrollaron extraordinaria y simultáneamente: el aumento de la población mundial y los «avances igualmente espectaculares en la especialización profesional y en la integración organizativa», ampliando así «las posibilidades de relaciones entre los hombres». En síntesis:

Las cadenas de interdependencia entre ellos no solo se alargaron, sino que también se diferenciaron. La red de sus imbricaciones se volvió más compleja y la necesidad

8 SIMMEL, Georg: “A metrópole...,", p. 17 (traducción libre). 
de una determinación temporal exacta de la totalidad de las relaciones se hizo cada vez más apremiante, a punto de configurarse como el medio indispensable de su regulación ${ }^{9}$.

Todos esos procesos también se podrían comprender por lo que el sociólogo americano Steven Spitzer denomina «imposición de reglas calculables para disciplinar las relaciones sociales ${ }^{10}$. La previsibilidad referida por Elias y Spitzer es, por lo tanto, la condición necesaria para viabilizar la sincronización cotidiana de la sociedad industrial, y en el espacio de la metrópolis más que en ningún otro.

Históricamente distintos mecanismos se han desarrollado para la construcción de dicha previsibilidad. Las remodelaciones urbanas, siempre teniendo como paradigma la emprendida por el Barón de Haussmann en la París del II Imperio, no son de las menos importantes. La racionalización del espacio urbano y la consecuente optimización de su control tenían como objetivo retirar de la población pobre de las grandes ciudades el monopolio del conocimiento y del dominio sobre parcelas estratégicas del territorio de las ciudades. Sin ello, la abarcadora capilaridad del Estado Moderno, que siempre encontraría a su súbdito cuando lo necesitara - para la guerra, para el trabajo o para el tributo - sería mucho más difícil. Además, el consumo y la circulación de mercaderías podrían destrabarse y satisfacer las necesidades del ascendiente capitalismo industrial. Las políticas sanitarias que íntimamente se le asociaron buscaban eliminar otras amenazas a la previsibilidad, como las epidemias, capaces de colapsar el comercio y la producción a la vez. La identificación civil obligatoria, proceso un poco posterior, pretendía, por otra parte, acabar con el anonimato perturbador de las multitudes urbanas, reindividualizando a sus integrantes. La valoración del trabajo y la correlata penalización de la «desocupación», a su vez, trataban de localizar cada individuo en un punto del proceso productivo y asegurarle una ocupación útil. Centros medievales laberínticos, sucios y superpoblados, multitudes amenazadoras sin cara y sin nombre y «vagos» sin trabajo y sin rumbo representaban trabas inaceptables a la previsibilidad y a la sincronización de la sociedad moderna y de la metrópolis industrial que tales estrategias trataban de eliminar.

Sin embargo, la gran ciudad moderna no podría ser explicada solamente por el triunfo de esos dispositivos estabilizadores. El paisaje urbano era a la vez el locus del caos y del orden, de la sincronía y de la disensión, de lo previsible y de lo accidental, de lo regulado y de lo irregular. En realidad, las estrategias estabilizadoras solo adquirían sentido y urgencia con la existencia permanente del desorden y de la amenaza. De ahí que la metáfora maquínica pudiera surgir como una utopía de la estabilización social, capaz de producir una sincronización sin ruidos o perturbaciones. El automatismo de la máquina expresaba la previsibilidad perfecta, y por lo tanto, la posibilidad de una ciudad plenamente armónica, sin conflictos y sin contradicciones. Una de las hipótesis centrales de este estudio es que dicha utopía encontró repercusión social im-

\footnotetext{
9 ELIAS, Norbert: Sobre o tempo, Rio de Janeiro, Zahar, 1998, p. 116 (traducción libre; publicado originalmente en 1984, en Frankfurt am Main, con el título Über die Zeit. Arbeiten zur Wissenssoziologie II).

10 SPITZER, Steven: "The racionalization of crime control in capitalist society", en Stanley COHEN y Andrew SCULL (eds.): Social Control and the State, Oxford, Basil Blackwell, 1986, p. 314 (traducción libre). 
portante en el período de entreguerras, a punto de traducirse en la producción cultural en general y en el lenguaje del cine en particular.

\section{La sincronización urbana en el cine}

En ese sentido, las ya citadas sinfonías urbanas son de obvio interés. La metáfora de la ciudad-máquina se expresa en forma particularmente contundente en São Paulo, Sinfonia...En la ciudad presentada por los directores húngaros hay poco lugar para la disonancia y el desorden ${ }^{11}$. Los cuerpos, las instituciones, los tranvías y las fábricas componen allí una sinfonía sin ruidos, cada cual en su lugar y desempeñando su papel. La película sirve además para revelar al espectador las tramas invisibles al hombre común que hacen que la ciudad funcione y que establecen interdependencias entre sus diversos momentos y lugares, solo aparentemente desarticulados entre sí. De ahí que la producción de leche componga una secuencia con la imagen de un camión de distribución que culmina con el brazo de una muchacha recogiendo la botella en la ventana de su casa. Se hizo una operación semejante con el periódico, con igual preocupación por revelar la sincronía entre su producción en la imprenta y su compra por los individuos ajetreados en las calles y en los tranvías de la ciudad, pasando por su distribución a los pequeños y ágiles vendedores.

Es evidente que para construir esa imagen sinfónica, los autores tuvieron que proceder a distintos ocultamientos. La miseria, las casas de vecindad, las insurrecciones sociales, las inundaciones y las epidemias, por ejemplo, no forman parte de la São Paulo armónica del celuloide. La noche de São Paulo tampoco mereció convertirse en imagen, diferentemente de lo que ocurre en la sinfonía berlinesa. El día de la ciudad termina con el fin de la jornada de trabajo, lo que articula la película con una de las más privilegiadas construcciones identitarias de São Paulo: el trabajo es lo que le confiere sentido a la ciudad.

En Berlín, Sinfonía de una gran ciudad, realizado dos años antes de la película brasileña, la imagen maquínica de la ciudad es más moderna, lo que evidentemente fue facilitado por el soporte mismo de la película, la ciudad de Berlín, en todos sus aspectos más plena de modernidad que la São Paulo del final de los años 1920. Tal vez por ello la película alemana es menos ostensivamente optimista y apologética. Al lado de la fascinación por la máquina, por la tecnología y por el tren, por ejemplo, aparecen recurrentes referencias a los vértigos que produce la metrópolis industrial, culminando en la escena de un supuesto intento de suicidio de una mujer desesperada que se prepara para tirarse de un puente. De cualquier modo, Ruttmann no se aleja del ideal maquínico. Las ambigüedades de la ciudad están de alguna manera reflejadas en la película, pero no permiten que el resultado sea la imagen de una Berlín desagrega-

11 Sobre esa película ver también MACHADO, Rubens: São Paulo em movimento: a representação cinematográfica da metrópole nos anos 20, São Paulo, Escola de Comunicações e Artes da Universidade de São Paulo, 1989; y FERLA, Luis: “A cidade-máquina em São Paulo, Sinfonia da Metrópole”, Cadernos de Antropologia e Imagem, 23 (2006), pp. 81-96, que comparten varias de las perspectivas analíticas aquí referidas, pero dedicadas solamente al filme brasileño en cuestión. 
da y fragmentada. El mismo director llegó a explicitar esa opción metodológica para filmar la ciudad:

Muchas de las tomas más bonitas tenían que quedar fuera porque no podría surgir de ellas un libro ilustrado, sino algo como la estructura de una máquina complicada que sólo puede empezar a funcionar si cada una de sus menores pieza se encaja con la mayor precisión en la otra ${ }^{12}$.

Algunas de las estrategias para la construcción de esa ciudad-máquina que Ruttmann utiliza están presentes en la película sobre São Paulo y son recurrentes en varias otras películas del período. Por ejemplo, convertir el tiempo y su medición en objetos en sí pertinentes al cine. Ya se ha mencionado aquí el análisis de Elias que ve en el tiempo de la fábrica un mecanismo central de la sincronización que la sociedad industrial históricamente ha sido capaz de producir. Solamente un tiempo abstracto, universal y fragmentado lo posibilitaría. Thompson, en un artículo ya clásico sobre el tema, hace la historia del paso de una noción de tiempo preindustrial, que se mide teniendo como referencia las tareas cotidianas, y por lo tanto no separado de la vida, al tiempo que nace en la fábrica moderna, preciso, subdivido e igual para todos ${ }^{13}$. Los aumentos dramáticos y correlatos de la división del trabajo, auxiliados por los sucesivos incrementos del grado de maquinización de la producción, convirtieron la generalización de ese nuevo tiempo en una necesidad primordial del ascendiente capitalismo industrial. Por otro lado, la centralidad de la fábrica en la sociedad moderna hizo que ese fenómeno del espacio fabril pasara a la ciudad industrial, y de ésta al conjunto de la sociedad ${ }^{14}$. Así que, si los obreros de determinada fábrica tenían que estar allí a una determinada hora de la mañana, con la debida prontitud para el arranque puntual de las máquinas, para hacerlo tenían que tomar el tranvía igualmente en una hora precisa, lo que ampliaba la disciplina del tiempo hacia el conductor y el cobrador involucrados, por ejemplo.

Un problema derivado de la nueva noción de tiempo fue su efectiva distribución, pues la disponibilidad de la consulta a la hora es lo que de hecho viabilizaría la sincronización. Es ese el papel de los grandes relojes en torres y grandes edificios en las metrópolis modernas. Omnipresentes, permitían que los cuerpos humanos calibraran sus movimientos a lo largo del día para producir la Sincronía cotidiana. En varias de las películas analizadas el reloj, pequeño o grande, en la fábrica o fuera de ella, es objeto privilegiado de la cámara. Su aparición es recurrente y se da por «derecho propio» y en forma no contingente, constituyendo allí el tema mismo de la película.

En São Paulo, Sinfonia..., hay una secuencia en la que los transeúntes apresurados consultan sus relojes para ajustar la velocidad de sus desplazamientos. La centralidad y el foco están en los relojes mismos, de bolsillo o de pulsera, y en el gesto de consultarlos (Figura 1).

12 Citado por MACHADO, Rubens: São Paulo em movimento..., pp. 32-33 (traducción libre).

13 THOMPSON, Edward. P.: "Time, work-discipline, and industrial capitalism", Past and Present, 38 (1967), pp. 56-97.

14 La expresión globalizada de ese proceso es la elección del meridiano de Greenwich como referencia para la hora mundial, en 1884 (Para una excelente contextualización histórica de la mundialización de la medición del tiempo ver GALISON, Peter: Relojes de Einstein, mapas de Poincaré, Barcelona, Crítica, 2005). 


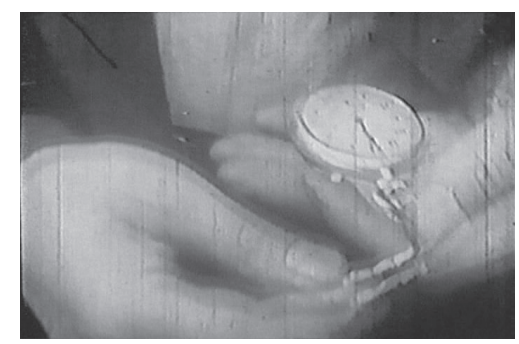

Figura 1

En Berlín, Sinfonía ... es a un gran reloj en una torre de la ciudad que se le confiere protagonismo. Al inicio del primer acto, dedicado al amanecer de la ciudad, los primeros movimientos de lo que se convertiría en una sinfonía veloz, intensa y multitudinaria son precedidos por algunas imágenes de dicho reloj indicando las cinco de la mañana (Figuras 2 y 3 ).

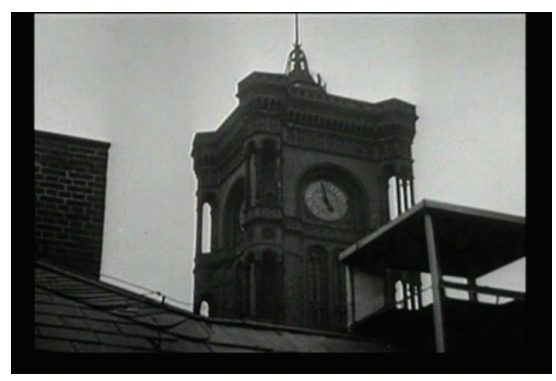

Figura 2

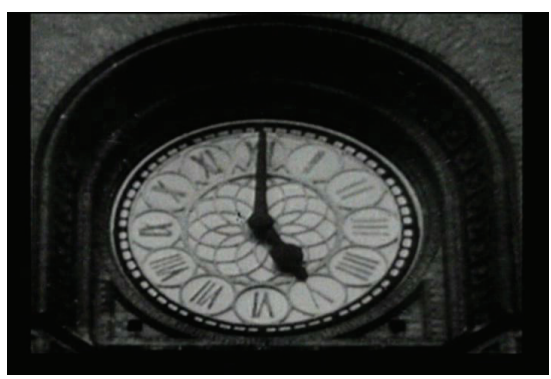

Figura 3

Aún en 1927, encontramos en Metrópolis, de Fritz Lang, la presencia implacable del reloj imponiendo su ritmo de trabajo y atando el obrero a su máquina hasta su último aliento de energía, hasta el último segundo del último minuto de su turno. Sintomáticamente, la máquina misma se parece a un reloj y el operario trata de ajustar sus manecillas en búsqueda de una imposible sincronización con lámparas que se encienden y apagan. En una de las numerosas metáforas bíblicas de la película, el trabajador fatigado aparece preso a esas manijas como a una cruz en versión moderna e industrial (Figura 4).

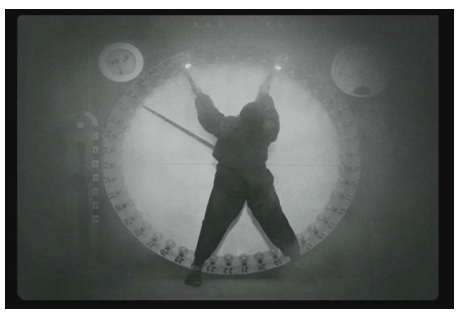

Figura 4 
Chaplin, en Tiempos Modernos, pone un gigantesco reloj de faz rectangular tomado de frente y ocupando casi todo el espacio de la pantalla, significativamente como la escena que abre la película (Figura 5). La interiorización de la disciplina fabril y del tiempo de la fábrica aparece en otra escena que comparte la crítica irónica que impregna toda la película. En pleno «colapso nervioso» debido a la imposición de un trabajo que convertía a los obreros en hombres-máquinas, Charlot entra corriendo hacia el interior de la fábrica, de donde había salido persiguiendo a una mujer y para donde volvía perseguido por un policía. Pero antes de entrar nuevamente al ambiente de las máquinas y de los obreros, pasa por un reloj de control y aunque en pleno «desvarío» y en medio a una fuga acelerada, no deja de «fichar», como se había condicionado maquinalmente a hacer cada vez que pasaba por allí (Figura 6).

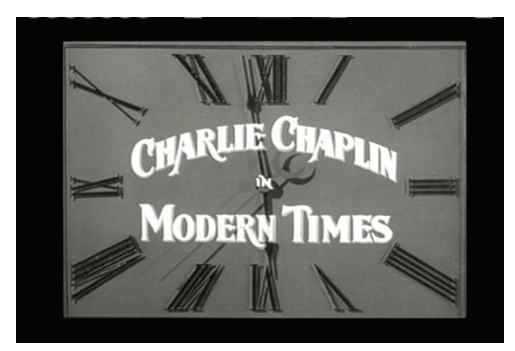

Figura 5

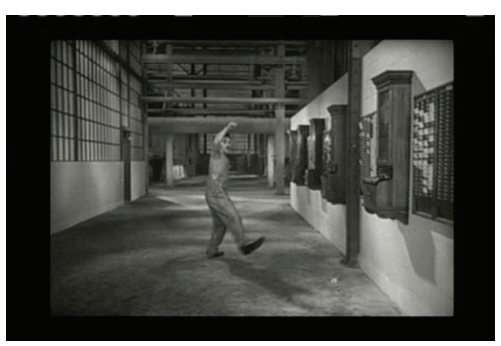

Figura 6

La misma sincronización industrial, condición central para la sincronización urbana, es uno de los temas centrales de la película. La racionalización científica del trabajo, que culminó en los movimientos taylorista y fordista y pasa por la cinta de las modernas líneas de montaje, creó grados cada vez mayores de interdependencia y sincronía entre los gestos individuales de cada operario, a su vez cada vez más simplificados y fragmentados. Chaplin pretendió hacer una crítica a ese proceso, denunciando la deshumanización que implicaba. El desajuste de su personaje a las draconianas condiciones del trabajo, que imponían ritmos maquínicos inflexibles a los operarios, los llevó al colapso, al suyo propio y al de toda la fábrica. La sincronización aquí aparece amplificada en la demostración de su imposibilidad a partir del desajuste de tan sólo una pequeña parte que pone en riesgo la producción y todo el complejo fabril (Figura 7).

René Clair, cinco años antes de Chaplin, había llevado al cine la misma crítica, con una escena de colapso en la línea de montaje estructuralmente idéntica. En ; Viva la libertad! también hay un operario que no logra acompañar el ritmo que la fábrica maquinizada exigía. La crisis surge con su descompás con el flujo automatizado, pero también una segunda vez cuando se cae el pañuelo de su «amada» en la cinta, lo que lo lleva a intentar rescatarlo y a nuevamente «amontonarse» con los colegas de trabajo (Figura 8). Sea por una fatiga acompañada de un agotamiento nervioso, sea por la incapacidad de mantener la atención, seguida de una expresión de afecto o pasión, ambos cineastas están contraponiendo la imposibilidad del hombre asimilar la máquina y denunciando la violencia de la sincronía fabril. 


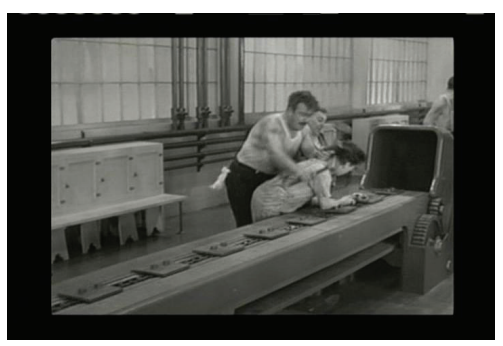

Figura 7

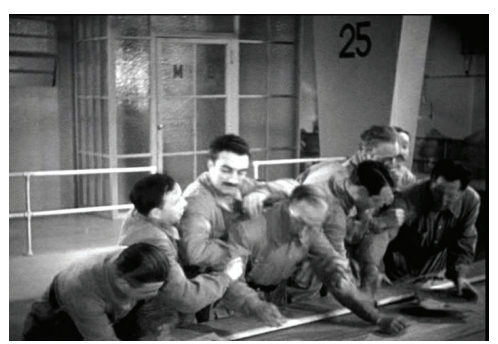

Figura 8

Retomando la película de Chaplin, no hay soluciones de continuidad entre el espacio de la fábrica y el territorio de la ciudad, en lo que se refiere a los temas aquí planteados. Walter Benjamin ya afirmaba que «a la vivencia del choque, sentida por el transeúnte en la multitud, corresponde la "vivencia" del obrero con la máquina»" ${ }^{15}$. Así que, si un hombre-máquina es condición para la existencia de la ciudad-máquina, las violencias e imposibilidades asociadas a esta última pueden ser legítimamente derivadas del intento de la realización de aquél. Tanto en un caso como en el otro, permanecen las inexorabilidades mecánicas como fuente de las mayores amenazas, bien en forma de tranvías o automóviles veloces, bien como cintas transportadoras y máquinas fabriles. La escena del fracaso de Charlot al intentar cruzar una calle ajetreada, aunque no incluida en la versión final de la película, tiene exactamente ese sentido (Figura 9). También aquí los reflejos y las sensibilidades del cuerpo humano no son suficientes para acompañar los ritmos y flujos que se le imponen. Hecho interesante es que hay una escena de igual contenido en São Paulo, Sinfonia... en la cual una viejecita trata de cobrar valor para dejar la acera e invadir el terreno asustador, arisco e imprevisible del carril de automóviles (Figura 10). El cuerpo del payaso, desfasado por definición, y el cuerpo del anciano, ya incapaz de redefinir sus condicionamientos, forjados en un mundo premoderno, son así convenientes para amplificar la demostración del poder coercitivo de la Sincronía, al mismo tiempo que aluden a su inexorabilidad.

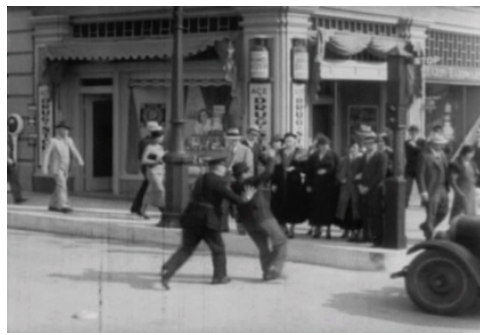

Figura 9

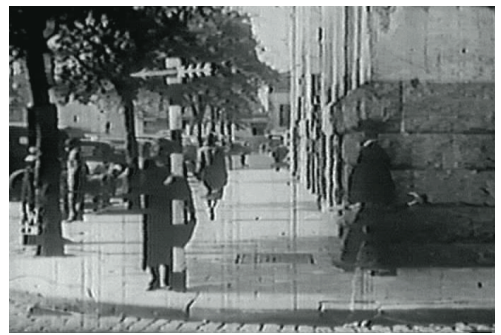

Figura 10

15 BENJAMIN, Walter: Charles Baudelaire: um lírico no auge do capitalismo, São Paulo, Brasiliense, 2000, p. 126 (traducción libre; la edición brasileña fue hecha a partir de la obra Auswahl in drei Baenden, publicada por la editorial alemana Suhrkamp). 
También se pueden relacionar esos discursos fílmicos al desarrollo de una modalidad de biopoder característico de la sociedad industrial, a saber, la preocupación por la optimización del balance energético de la clase operaria, para evitar su agotamiento físico y aumentar su productividad, con estrategias como control de la alimentación y los modos de vida, según las reflexiones de Michel Foucault ${ }^{16}$. Justamente cuando plantea dichas cuestiones, el autor francés proporciona posibilidades interesantes de interfaz con la obra The Human Motor, de Anson Rabinbach, centrada en la priorización del tema de la energía humana y de la fatiga que, para el autor, tuvo lugar en las sociedades industriales en expansión desde finales del siglo XIX hasta por lo menos el segundo post guerra del siglo pasado ${ }^{17}$. En ese período, la metáfora del motor humano se difundió con fuerza en los ambientes científicos y culturales, identificando cuerpo humano y máquina industrial, concebidos como mecanismos destinados a transformar energía en trabajo mecánico. La única perturbación que parecía dificultar la plena realización de la metáfora residía en la resistencia del cuerpo humano al trabajo perpetuo, de ahí la centralidad que el tema de la fatiga acabaría por asumir ${ }^{18}$. Tratar de determinar sus orígenes, sus formas de expresión y cómo evitarla o al menos aminorarla pasó, entonces, a significar una estrategia de defensa nacional contra una seria amenaza al progreso y a la expansión económica ${ }^{19}$. La tesis de Rabinbach de que la importancia asumida por el tema haya posibilitado su diseminación desde los ambientes científicos e industriales al universo cultural viene a reforzar la hipótesis asumida en ese artículo, la de que el cine acabó por reflejar considerablemente la cuestión ${ }^{20}$.

Hay otra secuencia de la película de Chaplin que también remite fuertemente a esa discusión. Una máquina destinada a ahorrar la energía del trabajador durante la comida es presentada por su idealizador al dueño de la fábrica en la que trabaja Charlot. Se trata de un artilugio electromecánico que supuestamente debería permitir al operario alimentarse en su local de trabajo y casi que con la total pasividad de su cuerpo, encargado tan solo del acto de comer. Para demostrar su funcionamiento, eligen a Charlot como cobaya. Debidamente inmovilizado junto a la máquina, mira perplejo sus movimientos, al mismo tiempo que se somete a lo que le concierne en dicha empresa: masticar y tragar. Una mesa giratoria frente a él organiza la sucesión de los platos que se servirán, y los alimentos se encaminan directamente a la boca de Charlot con la ayuda de un brazo mecánico. Entre un plato y otro, una servilleta también automática realiza periódicamente su tarea de limpieza. Evidentemente todo termina mal, la máquina se descontrola totalmente, pasa a operar anárquicamente y

16 Ver FOUCAULT, Michel: História da sexualidade: a vontade de saber, Rio de Janeiro, Graal, 2001 (traducción del original en francés Histoire de la Sexualité: I La volonté de savoir); y FOUCAULT, Michel: Em Defesa da Sociedade, São Paulo, Martins Fontes, 2000 (publicada originalmente en francés con el título Il faut défendre la société).

17 RABINBACH, Anson: The human motor: energy, fatigue, and the origins of modernity, New York, Basic Books, 1990.

18 RABINBACH, Anson: The human motor..., p. 2.

19 RABINBACH, Anson: The human motor..., p. 22, y pp. 208-210.

20 En ese sentido, es significativo que los estudios de Marey sobre el movimiento del cuerpo humano, considerados legítimamente como pertenecientes a los fenómenos del «precine», representen para el autor una convergencia entre modernidad social y cultural (RABINBACH, Anson: The human motor..., pp. 84-88). 
de modo bastante lesivo a su «piloto de pruebas». La demostración malogra espectacularmente, traduciendo una vez más la crítica de Chaplin a la excesiva mecanización del mundo industrial en que vive, tema que pasa por toda la película, pero, en forma más específica, la secuencia también alude a la obsesión por el referido ahorro de energía del trabajador, la cual debería ser estrictamente reservada al acto mismo de trabajar.

Retomando el tema de la racionalización del trabajo, no es otro el sentido de varias de sus estrategias que se venían desarrollando desde finales del siglo XIX. Mientras el taylorismo y sus correlatos codificaron y fraccionaron el movimiento humano eliminando sus «redundancias», el fordismo difundió las cintas transportadoras, minimizando el desplazamiento espacial del obrero y proporcionando un nuevo salto en la simplificación del gesto humano. Así mismo, se debe también a Ford la idealización de las «villas obreras», construidas junto a las fábricas, minimizando al mismo tiempo los desgastantes desplazamientos hasta el local de trabajo y permitiendo la vigilancia y la moralización de la rutina de sus habitantes, en última análisis también una estrategia de ahorro de energía. El tiempo y el espacio son así resignificados para viabilizar el cuerpo productivo del operario, sin embargo un cuerpo imposible en la perspectiva de Chaplin en Tiempos Modernos.

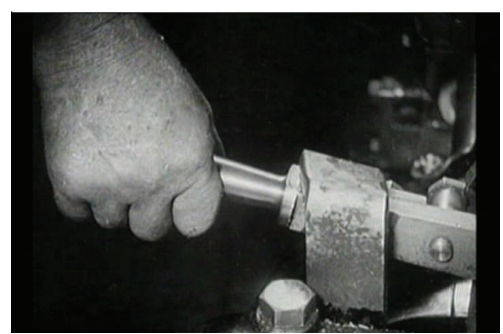

Figura 11

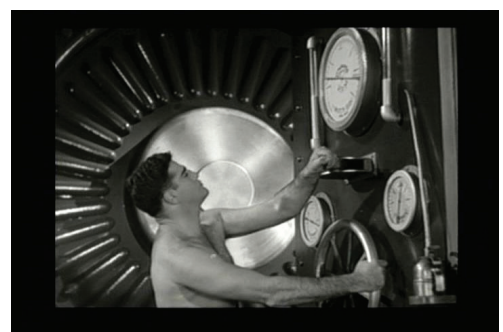

Figura 12

Además del reloj, los filmes analizados también permiten identificar otro objeto privilegiado en la construcción de la metáfora de la sincronización, sea en la fábrica, sea en la ciudad: la palanca. Su movimiento es capaz de instaurar y regular una serie de procedimientos interconectados. En Berlín, Sinfonía..., la larga secuencia dedicada a los procesos fabriles es precedida por el accionamiento casi ceremonioso de una palanca (Figura 11). También en Tiempos Modernos las palancas aparecen diversas veces con ese sentido. Cuando el director de la fábrica ordena al contramaestre que aumente la velocidad de la producción en determinada sección, eso se hace manejando un sistema de palancas (Figura 12). En la escena siguiente, la aceleración de la cinta produce un recrudecimiento de las condiciones corporales críticas del personaje principal. Sin embargo, en plena «crisis», es justamente utilizando las palancas que Charlot coordina la acción de sus colegas en la cinta y atrasa su captura, obligándolos a regresar al trabajo inmediatamente, cada vez que la producción se reinicia (Figura 13). El conjunto palanca-cinta-obrero se vuelve así un sistema que, una vez en movimiento, no permite vacíos, fallas o ausencias. Un momento antes, es moviendo 


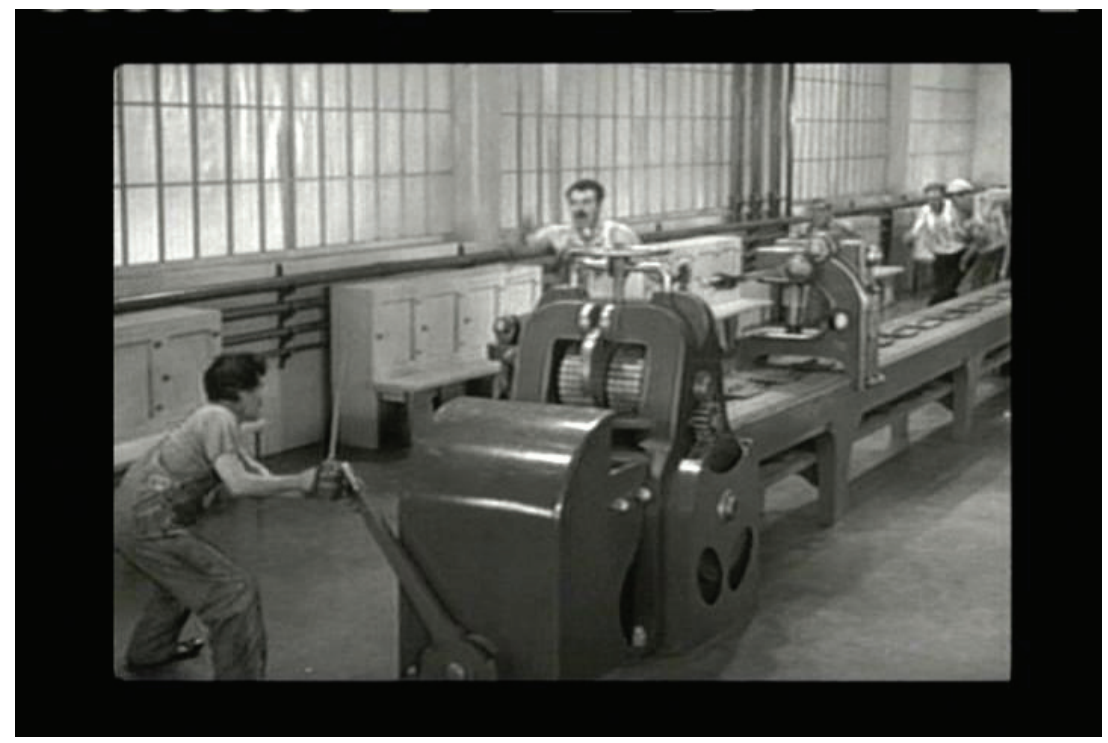

Figura 13

enloquecidamente el conjunto de palancas cercanas a la caldera que Charlot parece llevar la amenaza a la integridad de la fábrica y del proceso productivo al paroxismo, con llamaradas y humos induciendo la imaginación del espectador a incendios y explosiones (Figuras 14 y 15).

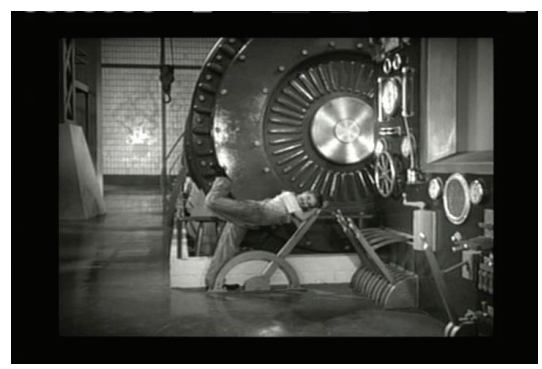

Figura 14

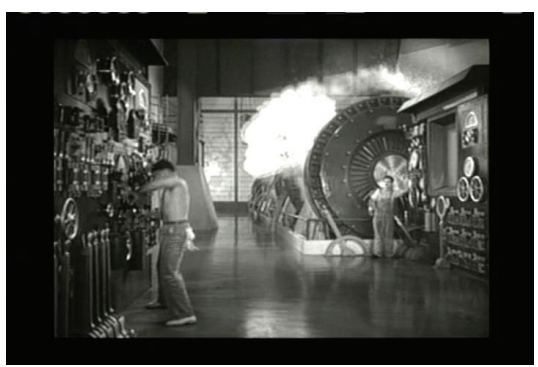

Figura 15

En São Paulo, Sinfonia... también encontramos muchas palancas filmadas esencialmente desde la misma perspectiva. También allí la producción fabril es precedida por el accionar de un sistema de botones y palancas (Figura 16). En las calles de la ciudad, manejando una pequeña palanca el policía coordina el tráfico urbano, en sí mismo una verdadera concretización para nuestros sentidos de la sincronía de la metrópolis industrial (Figura 17). Pero el paroxismo tal vez haya sido alcanzado por René Clair, en la película París dormido, en la que un científico literalmente detiene a toda la ciudad - y sus habitantes tienen los movimientos «congelados» - al accionar una palanca (Figura 18). 


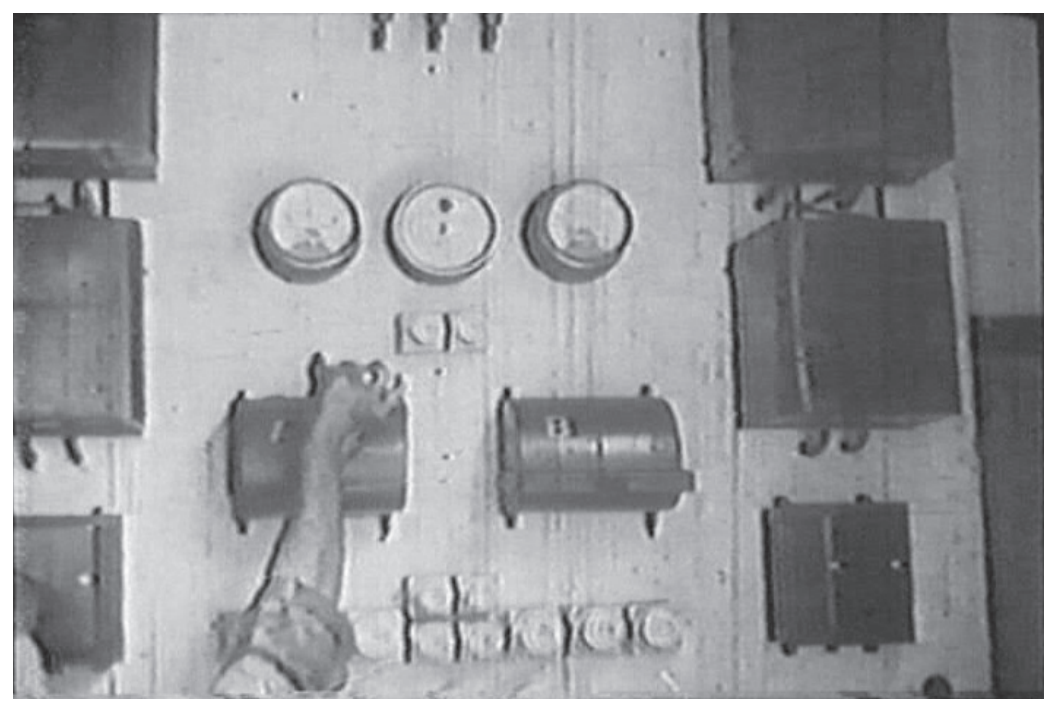

Figura 16

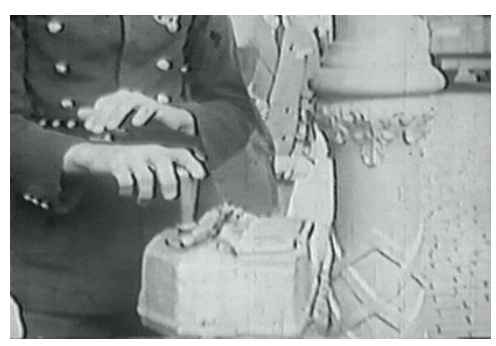

Figura 17

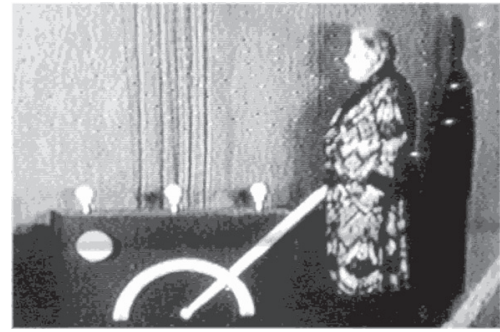

Figura 18

Walter Benjamin nos puede ayudar a comprender la metáfora de la palanca en el contexto de la afirmación de la modernidad. Él atribuye a la sociedad industrial la característica de generalizar dispositivos capaces de desencadenar una compleja sucesión de eventos a partir de un gesto sencillo:

Con la invención del fósforo, a mediados del siglo pasado, surge una serie de innovaciones que tienen una cosa en común: disparar una serie de procesos complejos con un gesto sencillo. La evolución se produce en muchos sectores; se vuelve evidente, entre otras cosas, en el teléfono en el cual el movimiento habitual de la manivela del antiguo aparato da lugar a descolgarlo. Entre los innúmeros gestos de conmutar, inserir, accionar etc., especialmente el "clic" del fotógrafo trajo consigo muchas consecuencias. Una presión del dedo era suficiente para fijar un acontecimiento por tiempo ilimitado ${ }^{21}$.

21 BENJAMIN, Walter: Charles Baudelaire..., p. 16 (traducción libre). 
La palanca, por consiguiente, es capaz de establecer una frontera nítida entre reposo y movimiento. La cuidadosa contraposición entre esos dos estados constituía incluso otra estrategia recurrente en la producción de sentido utilizada en las películas de sinfonías urbanas, reforzando una vez más la identidad maquínica de la gran ciudad. La percepción de la milagrosa sincronía que la metrópolis era capaz de construir resultaba amplificada por el contraste entre la quietud de la primera mañana y el bramido irresistible de la ciudad despierta y ajetreada. Es casi como si se concibiera el movimiento mismo del sol como partícipe en el complejo engranaje urbano, correspondiendo su desplazamiento ascendiente a la aceleración del movimiento de cuerpos y máquinas a ras del suelo urbano. En Berlín, Sinfonía... el primer acto, dedicado justamente a la primera parte del día, que va del amanecer al inicio de la operación fabril, se ocupa en presentar a los espectadores las calles vacías y silenciosas, el pequeño comercio con las puertas cerradas y las tiendas con las vidrieras todavía escondidas o sin espectadores, en combinación con las máquinas en reposo en el interior de las fábricas. Algo muy parecido hacen Kemeny y Lustig en São Paulo, Sinfonia... el cual tiene sus primeras escenas destinadas al amanecer del día y a las calles y plazas vacías. En ambas películas, a partir de ese escenario inicial, el ritmo gradualmente gana velocidad. En la película alemana, el proceso se inicia con el surgimiento de los primeros seres humanos, el primero de todos, sintomáticamente, un sereno que hace la ronda con su perro, sucedido por obreros a camino del trabajo. En medio a la apertura de las tiendas y la salida de los trenes del garaje, el flujo humano crece y adquiere la forma de un verdadero diluvio, que va llenando los espacios vacíos anteriormente enseñados para darles nuevos sentidos. Se forma la multitud, como que surgida del interior de la tierra - sensación que la toma de la salida de la estación de metro profundiza. A pesar del ritmo acelerado y de la composición desde una perspectiva caótica y fragmentada, no hay trabas visibles, y el resultado es la sensación de una coreografía perfecta entre cuerpos y máquinas.

Vertov utiliza esencialmente la misma estrategia en El hombre con la cámara, también haciendo anteceder al auge acelerado de la ciudad, el reposo y el silencio casi absolutos del inicio del día, aunque el paso del tiempo del día esté en esa película algo más barajado que en la de Ruttmann. Vertov enfatiza aún más el contraste entre máquinas en reposo y en movimiento antecediendo las distintas escenas en que aparecen en operación a lo largo de la película por una secuencia dedicada a mostrarlas silenciosamente apagadas. Por otro lado, cuando en actividad, muchas de ellas se presentan en articulación perfecta con los cuerpos humanos que a ellas se asocian como su trabajo, mecánica y precisamente articulados al ritmo impuesto por las máquinas. Contrariamente a las lecturas que se pueden hacer de las películas de Chaplin y de Lang aquí planteadas, en Vertov no hay ninguna crítica a la maquinización del hombre, todo lo contrario. Para el cineasta ruso, la impregnación tecnológica que las revoluciones industriales crearon era portadora de inmensas posibilidades. En lugar de someter al hombre, la máquina sería una prótesis para una relación mejorada de él con el mundo, siendo la cámara del cine la expresión arquetípica de esa potencialidad. Si la ciudad y la fábrica aún se parecían a valles de lágrimas en el tiempo de Vertov, no sería por responsabilidad de la tecnología y de las máquinas, sino del anquilosamiento de un sistema social que justamente impedía el más pleno desarrollo 
de ellas. Estamos aquí en franco territorio del constructivismo ruso y de su optimismo entusiástico con la modernidad ${ }^{22}$.

\section{Conclusión}

Así, la sincronización en gran escala que la metrópolis producía a cada veinticuatro horas, culminación de un proceso de larga duración de que se ocupó Norbert Elias, estaba entre los fenómenos urbanos que más impresionaban a sus contemporáneos más atentos y que por ello pudo ser tratado cinematográficamente con alguna prioridad, como vimos. En algunas de esas construcciones fílmicas, la utopía de la sincronización perfecta, sin ruidos, disensiones y perturbaciones, ganó expresión en la metáfora de la ciudad-máquina.

El deseo de convertir la fascinante sincronización real de las grandes ciudades de hormigón de la época en sincronización perfecta de las ciudades de celuloide puede conllevar el malestar con el panorama conflictivo y desagregador del mundo que emergió de la Primera Guerra y que en breve se enfrentaría a la dramática crisis de la Gran Depresión. Sin duda, la emergencia de los distintos fascismos y su énfasis en combatir la diversidad y afirmar una regimentación social unificadora y totalitaria expresaban una respuesta a ese fenómeno. Por otro lado, el cine de la época fue también capaz de hacer la crítica no sólo de las violencias que las estrategias de sincronización podrían implicar, señalando el cuerpo humano como su punto de aplicación último y central, sino igualmente revelando que en ese mismo cuerpo humano se encontraban sus límites absolutos e insuperables.

Sin embargo, es posible identificar un sustrato común alimentando esas dos vertientes fílmicas, la que hace apología entusiástica de la maquinización social y urbana, y la que le niega valor y denuncia su perversidad. Lo que subyace a todas las películas analizadas es la perplejidad por la nueva forma de organización de la vida social denominada metrópolis industrial. Si dicha perplejidad se puede traducir en un optimismo energético que no se contiene, como en Vertov, o en una pesadilla de tono expresionista, como en Lang, ambos comparten la necesidad de adueñarse de lo desconocido y proveerle un sentido urgente: la fascinación y el horror como dos caras de la misma moneda. Esa interpretación vuelve a sostenerse en la hipótesis que enfatiza lo inédito y lo radical de las transformaciones que la ciudad moderna produjo.

Así, con la pequeña muestra que aquí presentamos de la expresión cinematográfica de algunos de esos fenómenos, es posible reconocer que migraron a las pantallas muchas de las contradicciones, ambigüedades, aspiraciones y proyecciones que las grandes ciudades y sus protagonistas de entonces producían en su rutina. Y la ciudad-

22 Para expresiones textuales de ese entusiasmo, consultar los manifiestos de Vertov y de su grupo en VERTOV, Dziga; MICHELSON, Annette (ed.): Kino-Eye: The Writings of Dziga Vertov, Berkeley, University of California Press, 1984. Se puede trazar aquí algunos paralelos instigadores con el "Cyborg Manifesto" (A cyborg manifesto: science, technology, and socialist-feminism in the late twentieth century), de Donna Haraway, que identifica en las nuevas tecnologías genéticas y digitales del final del siglo XX diversas posibilidades emancipatorias (HARAWAY, Donna; KUNZRU, Hari; y SILVA, Tomaz Tadeu da: Antropologia do ciborgue: vertigens do pós-humano, Belo Horizonte, Autêntica, 2000). 
máquina pudo constituirse entonces en una de las más poderosas representaciones del imaginario de la época, sea como sueño o pesadilla.

\section{Bibliografía}

BENJAMIN, Walter: Charles Baudelaire: um lírico no auge do capitalismo, São Paulo, Brasiliense, 2000 (la edición brasileña fue hecha a partir de la obra Auswahl in drei Baenden, publicada por la editorial alemana Suhrkamp, s.f.).

ELIAS, Norbert: Sobre o tempo, Rio de Janeiro, Zahar, 1998 (publicado originalmente en 1984, en Frankfurt am Main, con el título Über die Zeit. Arbeiten zur Wissenssoziologie II).

FERLA, Luis: "A cidade-máquina em São Paulo, Sinfonia da Metrópole”, Cadernos de Antropologia e Imagem, 23 (2006), pp. 81-96.

FOUCAULT, Michel: Em Defesa da Sociedade, São Paulo, Martins Fontes, 2000 (publicada originalmente en francés con el título Il faut défendre la société, por la Editorial Gallimard en 1997).

FOUCAULT, Michel: História da sexualidade: a vontade de saber, Rio de Janeiro, Graal, 2001, (14 ${ }^{\mathrm{a}}$ ed.) (traducción del original en francés Histoire de la Sexualité: I La volonté de savoir, publicado por la Editorial Gallimard en 1976).

GALISON, Peter: Relojes de Einstein, mapas de Poincaré, Barcelona, Crítica, 2005. HARAWAY, Donna; KUNZRU, Hari; SILVA, Tomaz Tadeu da: Antropologia do ciborgue: vertigens do pós-humano, Belo Horizonte, Autêntica, 2000 (publicado originalmente con los títulos A cyborg manifesto: science, technology, and socialist-feminism in the late twentieth century, de Donna Haraway, en 1985, e You are the cyborg, the cyborg ancestry, de Hari Kunzru, en 1997).

MACHADO, Rubens: São Paulo em movimento: a representação cinematográfica da metrópole nos anos 20, São Paulo, Escola de Comunicações e Artes da Universidade de São Paulo, 1989.

PINTO, Maria Inez achado Borges: Cotidiano e sobrevivencia: a vida do trabalhador pobre na cidade de São Paulo (1890-1914), São Paulo, Edusp, 1994.

RABINBACH, Anson: The human motor: energy, fatigue, and the origins of modernity, New York, Basic Books, 1990.

SEVCENKO, Nicolau: Orfeu extático na metrópole: São Paulo, sociedade e cultura nos frementes anos 20, São Paulo, Cia das Letras, 1998.

SIMMEL, Georg: "A metrópole e a vida mental", en VELHO, Otávio Guilherme (org.), O fenômeno urbano, Rio de Janeiro, Zahar, 1967 (original publicado en 1903, con el título Die Großstädte und das Geistesleben). 
SINGER, Bem: "Modernidade, hiperestímulo e o início do sensacionalismo popular", en Leo CHARNEY y Vanessa SCHWARTZ: O cinema e a invenção da vida moderna, São Paulo, Cosac \& Naify, 2001 (publicado originalmente en 1995 por la University of California Press, con el título Cinema and the invention of modern life).

SPITZER, Steven: "The racionalization of crime control in capitalist society", en Stanley COHEN y Andrew SCULL (eds.): Social Control and the State, Oxford, Basil Blackwell, 1986.

THOMPSON, E.P: "Time, work-discipline, and industrial capitalism", Past and Present, 38 (1967), pp. 56-97.

VERTOV, Dziga; MICHELSON, Annette (ed.): Kino-Eye: The Writings of Dziga Vertov, Berkeley, University of California Press, 1984.

\section{Filmografía}

Berlín, Sinfonía de una gran ciudad (Berlin: Die Sinfonie der Großstadt, Walther Ruttmann, 1927);

El hombre con la cámara (Chelovek s kino-apparatom, Dziga Vertov, 1929);

Impresiones del viejo puerto de Marsella (Impressionen vom alten marseiller Hafen (vieux port), László Moholy-Nagy , 1929);

Lluvia (Regen, Joris Ivens, 1929);

Metrópolis (Metropolis, Fritz Lang, 1927);

Naturaleza muerta en Berlín (Berliner Stilleben, Berlin Still Life, László MoholyNagy, 1931);

París dormido (Paris qui dort, René Clair, 1925);

São Paulo, Sinfonía de la Metrópole (São Paulo, Sinfonia da Metrópole, Rodolfo Lustig e Adalberto Kemeny, de 1929);

Sólo las horas (Rien Que les Heures, Alberto Cavalcanti, 1926);

Tiempos Modernos (Modern Times, Charles Chaplin, 1936);

¡Viva la libertad! (A Nous la Liberte, René Clair, 1931). 